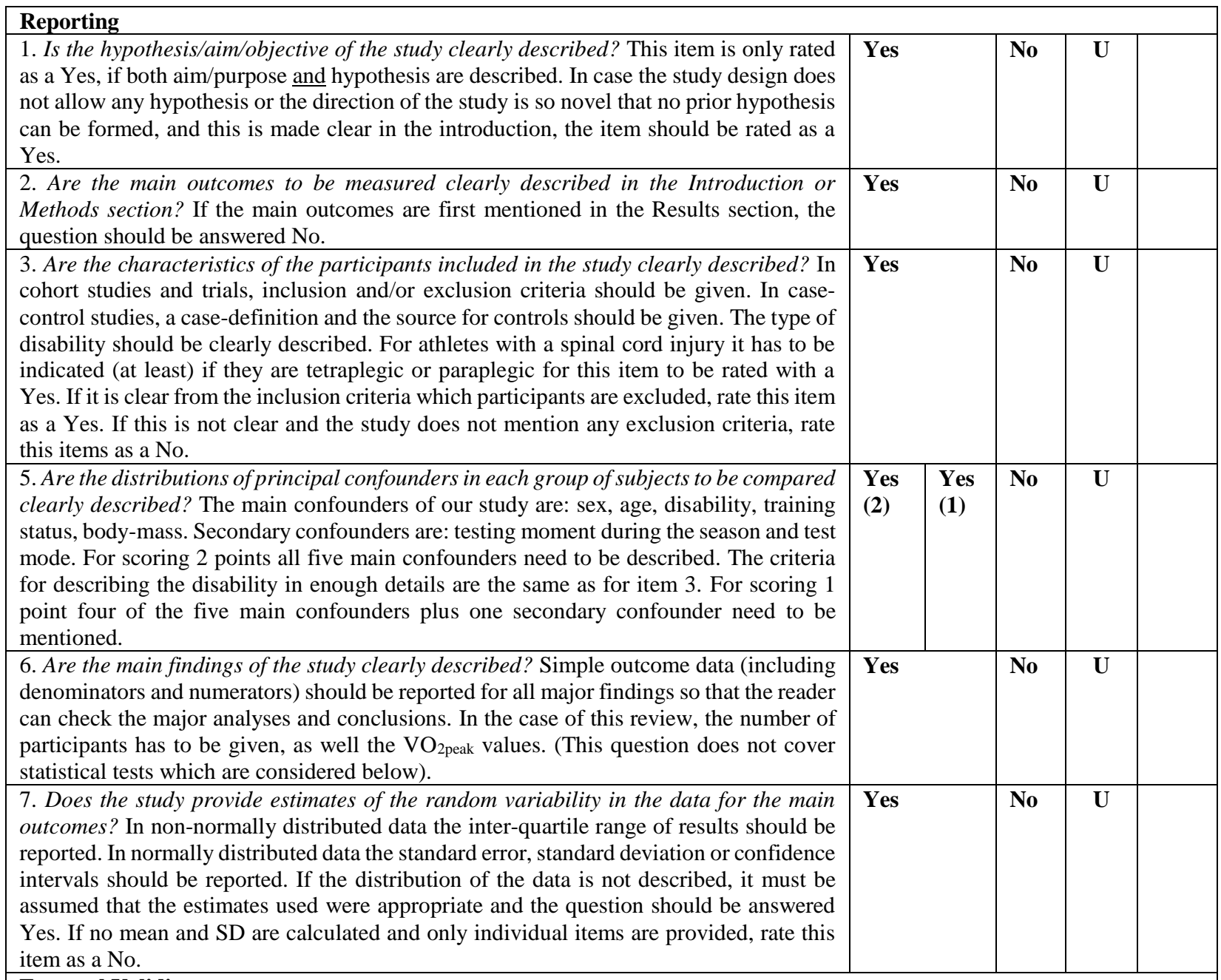

\title{
External Validity
}

All the following criteria attempt to address the representativeness of the findings of the study and whether they may be generalized to the population from which the study subjects were derived.

11. Were the subjects asked to participate in the study representative of the entire population from which they were recruited? The study must identify the source population for participants and describe how the participants were selected. Participants would be representative if they comprised the entire source population, an unselected sample of consecutive participants, or a random sample. Random sampling is only feasible where a list of all members of the relevant population exists. Where a study does not report the proportion of the source population from which the patients are derived, the question should be answered as unable to determine. The source population in our review is defined as athletes with a disability in the respective sports.

12. Were those subjects who were prepared to participate representative of the entire population from which they were recruited? The proportion of those asked who agreed should be stated. Validation that the sample was representative would include demonstrating that the distribution of the main confounding factors was the same in the study sample and the source population.

\section{Internal validity - bias}

20. Were the $\mathrm{VO}_{2 p e a k}$ measure used accurate (valid and reliable)? Studies have to report on the reliability and validity of the test equipment, test mode and if people with a disability (note: here we do not refer to athletes) were tested. For studies which refer to other work that demonstrates the outcome measures are accurate, the question should be answered as Yes. Both, pilot testing or referring to the work of others are sufficient to rate this item as a Yes. Referring to reliability and variability estimates performed on able-bodied participants is considered sufficient and the item will be rate as a Yes.

\section{Internal validity - confounding (selection bias)}

21. Were the participants in different intervention groups (trials and cohort studies) or were the cases and controls (case-control studies) recruited from the same population? The question should be answered unable to determine for cohort and case control studies where there is no information concerning the source of patients included in the study. The source population in this review is defined as athletes with a disability in the respective sports.

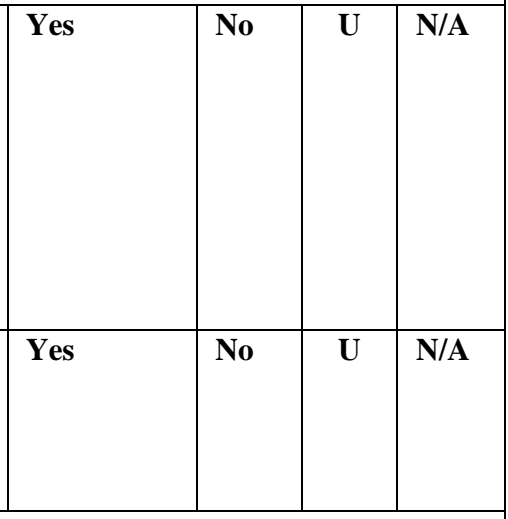

\begin{tabular}{|l|l|l|l|l|}
\hline & Yes & No & U & N/A \\
\hline & & & & \\
\hline$r$ & Yes & No & U & N/A \\
\hline & & & & \\
\hline
\end{tabular}




\begin{tabular}{|c|c|c|c|c|}
\hline $\begin{array}{l}\text { 22. Were study participants in different intervention groups (trials and cohort studies) or } \\
\text { were the cases and controls (case-control studies) recruited over the same period of } \\
\text { time? For a study which does not specify the time period over which patients were } \\
\text { recruited, the question should be answered as unable to determine. }\end{array}$ & Yes & No & $\mathbf{U}$ & N/A \\
\hline $\begin{array}{l}\text { 25. Was there adequate adjustment for confounding in the analyses from which the } \\
\text { main findings were drawn? This item should be rated as a Yes, if the criteria for } \\
\text { verification of maximal effort are explicitly stated. Verification of maximal effort } \\
\text { should at least contain two of the following five minimum criteria: } 1 \text { ) respiratory } \\
\text { exchange ratio (RER) of } 1.05 \text { or higher, } 2 \text { ) a concentration of lactate in blood ([La- }{ }^{-} \text {) of } \\
7 \text { mmol/liter or greater, and 3) a subjective rating of perceived exertion (RPE) with a } \\
\text { BORG scale score of } 15 \text { or higher, } 4 \text { ) no increase in } \mathrm{VO}_{2} \text { despite further increases in } \\
\text { intensity or 5) reaching a maximal heart rate within } 10 \text { beats/min of an individual's age- } \\
\text { predicted maximum (calculated as } 220 \text { - age). Alternatively, the verification of } \\
\text { maximal effort is also considered to be achieved in case a verification test was } \\
\text { performed. Any studies which did not report on the verification of maximal effort or } \\
\text { which include criteria below the above described, should be rated with a No. Deviating } \\
\text { criteria should be specifically noted in the comments box provided to the right. }\end{array}$ & Yes & No & $\mathbf{U}$ & N/A \\
\hline
\end{tabular}

Yes (1 point), No (0 points), $\mathrm{U}=$ unable to determine (0 points), N/A = not applicable (question excluded from quality analysis)

\section{References}

1. Downs SH, Black N. The feasibility of creating a checklist for the assessment of the methodological quality both of randomised and non-randomised studies of health care interventions. $\mathrm{J}$ Epidemiol Community Health. 1998;52(6):377-84. 